\title{
Sistema comercial e instituciones en los Países Bajos modernos
}

\section{Miguel Ángel Echevarría Bacigalupe ${ }^{1}$ \\ Universidad del País Vasco. Bilbao (España)}

Resumen: Este trabajo analiza la evolución del sistema comercial e institucional en los Países Bajos durante los siglos XVI al XVIII.

Palabras Clave: Países Bajos; 1500-1800; instituciones económicas

\begin{abstract}
This paper analyses the evolution of the commercial and institutional systems in the ancient Low Countries from the 17th to the 18th Centuries.
\end{abstract}

Keywords: Low Countries; 1500-1800; economic institutions

\section{1.- Introducción a la temática}

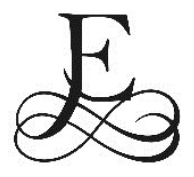

I objetivo del presente escrito es analizar la evolución del sistema comercial propio de los Países Bajos en un tiempo histórico largo (de longue durée), que va del siglo XVI a comienzos del XIX, y su relación con el resto de instituciones dentro de su ámbito espacial propio. No estaría de más, antes de empezar, que planteáramos una serie de definiciones, ya que es el método más seguro para analizar y entender un problema. Primeramente, se entiende por sistema comercial la interacción de diversos elementos en torno a la actividad comercial. Dichos elementos son

\footnotetext{
${ }^{1}$ http://org.orcid 0000-0002-9587-0986

(C) 2018 Philostrato. Revista de Historia y Arte
} 
principalmente el capital humano (cantidad y calidad de los participantes en el sistema), el subsistema de transporte (marítimo y terrestre), la financiación (pública, privada), el sector transformador (en este caso, preindustrial) y los intereses políticos. La forma que daremos a este sistema mercantil está inspirada en el modelo económico de Alberto Struzzi ${ }^{2}$; sería pues una especie de planetario cuyo centro (o 'sol') sería el comercio, con un conjunto de subsistemas interactuando a su alrededor. Como parte a su vez de un sistema más complejo, estaría en estrecha relación con el sistema político, muy especialmente en un tiempo en que los poderes públicos no se mostraban muy dispuestos a conceder libertad de movimientos a una actividad tan remuneradora como la mercantil, que, por si fuera poco, podía utilizarse como arma política (pactos, tratados) y aún bélica (embargos, guerras comerciales).

Sabido es que el comercio tiene particular relevancia en el sistema preindustrial de los siglos modernos. Veamos las razones más señaladas. Primero de todo, porque facilita la elasticidad espacial indispensable al crecimiento económico. Otras razones son que no está sujeto a grandes dotaciones de capital fijo; que el factor capital es superior al factor trabajo; que no requiere grandes innovaciones técnicas (aunque esto no significa que le sean indiferentes); que posee unos gastos fijos poco elevados; y que a cambio provee de costes constantes (esto es, a mayor coste, mayor productividad, y por ende, mayor beneficio). Desde otra perspectiva, el comercio viene bien al poder político porque genera riqueza, es decir, mayores ingresos fiscales al príncipe y bienestar a sus súbditos, porque es un medio de comunicación eficaz, y como se ha dicho, porque puede utilizarse como arma de paz o de guerra, según las circunstancias lo precisen. Por eso la diplomacia tiene mucho que ver en el asunto. Los tratados de paz incluirán generalmente un añadido comercial entre las partes que hace de las ventajas materiales un poderoso señuelo para conseguir el fin de las hostilidades, y a la vez lo consagra como premio. La labor del diplomático se dobla de tareas comerciales y financieras sin quedar necesariamente afectado por ellas, dado su alto rango. Tuvo que venir la industrialización para desposeer al sector mercantil de su primacía, pero aun así continuará siendo un elemento clave en el crecimiento y desarrollo económicos.

Para seguir acercándonos al problema central que ocupa estas páginas, hemos de definir a la institución misma. De acuerdo con Henri Lefevre ${ }^{3}$, toda institución es gobernanza de un espacio, o sea, su herramienta de control; así que mientras ese espacio perdure, aquélla perdurará. El cometido primordial de toda institución es por consiguiente gobernar, gestionar (mejor o peor, eso ahora no importa) un espacio encomendado. $Y$ tras el espacio, el tiempo, que añade solidez a esa institución otorgándole rutina administrativa.

\footnotetext{
2 Miguel Ángel Echevarría Bacigalupe, Alberto Struzzi, un precursor barroco del capitalismo liberal, (Leuven: Universidad, 1995), pp. 230-231.

3 Henri Lefevre, La producción del espacio, (Madrid: Capitán Swing Libros, 2013), p. 271.
} 
Una institución ¿controla y administra de manera absolutamente efectiva? La existencia y aun necesidad de instituciones no implica que los gobernados vean en ellas murallas infranqueables contra las que nada se puede hacer. Tanto más cuanto que las instituciones de Antiguo Régimen estaban muy poco centralizadas y en ocasiones se veían limitadas por leyes y privilegios especiales. El territorio que formaban las diecisiete provincias de los Países Bajos constituye un caleidoscopio institucional difícil de superar, al amparo del cual se cometieron toda clase de arbitrariedades que vinieron a sumarse al imperativo de supervivencia (o "efecto necesidad") causado por una guerra prolongada. Cómo pudo haber actividad económica e institucional, solo se entiende desde la estabilización de los espacios políticos de cada contendiente. El mayor cambio sobrevino desde la revuelta de 1566 en adelante ${ }^{4}$, pero su principal efecto fue duplicar en la mayor parte de los casos las instituciones preexistentes, adaptándolas a cada nuevo espacio. El viejo y el nuevo poder quieren suplir la ausencia o confusión con un nuevo entramado institucional que se inspira en modelos anteriores; luego, la guerra y sus alternativas impondrán cambios en la administración y la legislación que obedecen al efecto necesidad ya comentado.

Bajemos ahora a ras de suelo, al territorio mismo y sus avatares. Quizá más que en otras partes, la historia de los Países Bajos es un resultado de agregaciones, pero también de disminuciones. En su ámbito territorial, lo germano y lo latino se han venido encadenando sin solución de continuidad a lo largo del tiempo aprovechando el sistema fluvial en torno al valle del Rin. El imperio carolingio supuso un factor de unidad con el resto de territorios del entorno, aunque luego sufriera la atenuante de la desagregación feudal. La historia de los tiempos medievales y modernos es, para decirlo sucintamente, la lucha entre Francia y el Imperio por el control de esos apetecidos Países Bajos. Con todo, quedaríamos huérfanos de explicaciones sin aludir siquiera a un marco geográfico más amplio. En realidad, el área forma parte de un vasto corredor o pasillo que llega hasta el norte de Italia, una columna vertebral que concentra buena parte de la esencia de la Europa Moderna.

Pero ese espacio no estuvo en reposo, antes bien se movía, a veces violentamente, generando tiempos históricos distintos. Como miembro de la Monarquía Habsburgo, el País Bajo se verá sometido a integraciones espaciales de carácter superior. Primero, quedó inmerso en una amplia etapa de expansión espacial (1470-1770). Los Países Bajos se dividían tradicionalmente en el país par deçà y el país par delà, esto es, las provincias septentrionales (de Frisia a Luxemburgo) más el Franco Condado de Borgoña. Por diversas circunstancias que cuenta la historia política, la unificación de aquellos territorios no fue posible, y los Países Bajos con el Franco Condado se añadieron al ducado de Milán para entrar en los dominios imperiales. El

\footnotetext{
4 Para una comprensión del periodo entre Carlos V y la mitad del XVII, cf. Hugo de Schepper, 'Belgium Nostrum' 1500-1650. Over integratie en desintegratie van het Nederland, (Antwerpen, De Orde van den Prince, 1987).
} 
corredor, aunque en trozos, servirá a los designios de la Monarquía Hispánica tras la llegada al trono imperial de Carlos V, si bien con la separación de las provincias septentrionales quedará aún más dividido. Ello nos demuestra una cosa: cualquier pasillo territorial no constituye una entidad política por sí misma, pues su propia situación estratégica le convierte en presa disputada. Nada tiene de extraño pues que ese corredor clave fuera un espacio permanente de confrontación, de inestabilidad, de inseguridad. Desde fines del XVIII participó en un movimiento opuesto de fragmentación (1770-1830) por el que retrocederá hasta crearse un complejo institucional bajo la forma de Nación-Estado-Mercado (NEM) que fue a concretarse en dos reinos, el de Holanda y el de Bélgica.

\section{2.- Sistema institucional y economía (Siglos XVI-XVII)}

El capitalismo se expande por Europa occidental no sin tener que vencer las resistencias del viejo modo de producción feudal, con el que necesariamente ha de entenderse. La coexistencia implica adaptación y concesiones, aunque sin renegar de sus fundamentos, por cuanto se trata de modos de producción distintos. Para su fortuna, el capitalismo gozaba del apoyo de la realeza, deseosa de dar contenido material a su poder políticoinstitucional, que en el caso de españoles y portugueses se dobló de poder territorial. La gerencia del espacio político y la del económico coinciden, por lo que terminan en evidente alianza. Las instituciones del nuevo Estado se interesan cada vez más por la gestión y el control de los movimientos económicos exteriores en un momento histórico de expansión, de mirar hacia fuera en busca de recursos sin tener que tocar intereses vitales de las oligarquías, contentadas con mayor influencia en el ámbito interior a cambio de sumisión. Conviven pues capitalismo y feudo bajo la sombra de la realeza, pero su explicación tiene. En efecto, la lógica económica en el Antiguo Régimen, anclada al efecto necesidad, exige la no concentración espacial de las actividades, obligadas a dispersarse elásticamente para crecer o siquiera sobrevivir. Así, de los gremios y cofradías se pasa al trabajo doméstico, a las compañías (sea comerciales, financieras o de manufacturas) y a la Bolsa de productos como superadora de la feria medieval, tratando de racionalizar la dispersión. Banca municipal y privada apoyan el esfuerzo expansivo.

Todos tienen interés en ello. Para la corona, era una cuestión de precedencia sobre sus rivales. Para la nobleza, lo era la acumulación de recursos vinculados al suelo y al subsuelo. Para el naciente capitalismo resultaba una necesidad tanto más acuciante cuanto que debía alcanzar el nivel de reproducción, sin el que hubiera desaparecido. De esa múltiple expansión protagonizada por la monarquía hispana en Europa y fuera de ella formaron parte los Países Bajos, pero deseaban agregarse a ella como parte activa y no como territorio marginal, dada su potencialidad económica. Esto, 
sumado a intereses del entorno contrarios a los del núcleo central de la monarquía, hará que peticiones y protestas se acumulen hasta desembocar en rebelión por parte de aquellos estados.

La guerra (a la vez civil y contra el soberano) que estalla a mediados del XVI entremezcla dramáticamente los destinos de Iberia y de los Países Bajos. Suele decirse que desde entonces los españoles quedan atrapados en una problemática ajena a su "destino manifiesto", que sería ocuparse de América, de África y del Mediterráneo. Se habla y no se para de la penosa herencia que recibieron los reyes de la Casa de Austria por sus lazos con el Imperio. Pero Flandes podría decir lo mismo respecto de su anexión a la corona española; de hecho, una de las causas de la rebelión fue el deseo de retomar su andadura propia en torno al Mar del Norte, el Báltico y el Mediterráneo.

Tras el estupor por la violencia de los acontecimientos y la ruptura en dos de la ciudadanía, Felipe II retoma la iniciativa buscando incrementar el control de aquellos territorios, cosa que no será fácil, pues de hecho se acaban perdiendo las provincias septentrionales. Aun respetando las particularidades locales, el rey tenía un sistema administrativo propio que irá consolidando en las provincias que se le mantengan obedientes. Si el ejército constituye la fuerza disuasoria ante cualquier veleidad juzgada inoportuna, el creciente aparato funcionarial de éste, instituciones nuevas como la Secretaría de Estado y de Guerra y el uso extendido de la contabilidad (eso sí, por partida simple $\left.{ }^{5}\right)$, constituirán las "cadenas de papel" necesarias para el funcionamiento del régimen. Quisiera yo recalcar la labor de los contables como administradores de lo volátil y gestores de lo consistente, a nivel político cuanto menos. Y es que, a más elasticidad espacial más contabilidad, o sea, más necesidad de control y cohesión. Ahora bien, ¿quién controla a los que controlan? Juicios de residencia y averiguaciones secretas pretenden dar cuenta de los malos gestores sin privarse de su indispensable concurso, no fuera que el castillo de naipes se viniese abajo.

Otro recurso con que cuenta la monarquía es la diversidad de los mismos Países Bajos. Un territorio de transición tan disperso impide por el momento la toma de conciencia "nacional"6, en beneficio de la adscripción a la causa regia, legítima, o la de los Estados Generales rebeldes. Es decir, a lo más que se llega es a un "patriotismo institucional", algo así como ese "patriotismo constitucional" de que tanto se habla hoy en día, extrapolando muy

\footnotetext{
${ }^{5}$ La partida doble no tuvo largo recorrido; cf. Esteban Hernández Esteve, Establecimiento de la partida doble en las cuentas centrales de la Real Hacienda de Castilla (1592), (Madrid: Banco de España, 1986). Bastaba con usar la partida simple, que correctamente utilizada, ponía en equilibrio la necesidad de información de los poderes públicos con los intereses estamentales de los oficiales contables; cf. Marco Ostoni, "La comptabilité publique entre théorie et pratique. Le cas de Milan au milieu du XVIIe siècle" en La comptabilité publique en Europe, 1500-1850, coord. A. Dubet y M.-L. Legay, (Rennes, Presses Universitaires, 2011), pp. 228-229.

6 Johan Huizinga, El concepto de la Historia y otros ensayos, (México, FCE, 1992), p. 240.
} 
erróneamente los tiempos pretéritos a los actuales ${ }^{7}$. Un sentimiento, como podrá deducirse, puramente de circunstancias. Lo más importante es que se entrelaza con los años una red de intereses estratégicos que impide abandonar los Países Bajos a su suerte, al centrarse allí las ambiciones europeas. Defender los territorios americanos (posiblemente esa fuera la auténtica herencia dañosa) implica poner una pica en Flandes y otra en el corazón de Europa, con el apoyo de las posesiones italianas. No se trata ya de voluntad, sino de obligación.

Hasta la tregua de 1609, los contendientes buscan arrebatarse uno al otro la totalidad del territorio. Se va creando velis nolis una situación de estabilidad territorial aceptable sin la que hubiera sido imposible acometer proyectos de expansión comercial y financiera como los realizados por las Provincias Unidas (VOC, WIC, Banco y Bolsa de Ámsterdam...). Ello no excluye el conflicto, pero sí lo modela. A lo militar se suma de manera decidida la guerra económica, es decir, la guerra comercial preferentemente. Embargos, bloqueos, capturas o represalias se suceden, pretendiendo romper la lógica económica que vincula desde siempre a las partes, ya que el comercio y las finanzas son actividades volátiles que necesitan de espacio. Pero lo político triunfa, y arrastra a los demás considerandos. Es una dialéctica entre libertad espontánea y coacción en un mundo necesitado, de escaseces. Cortar o molestar el comercio ajeno implica el hambre y la miseria para el enemigo (también para el bando propio, en ocasiones), lo que en una economía preindustrial supone la muerte, incluso para miles de personas. Fue un arma de guerra, y como tal, mataba. Eso escandalizará al mundo posterior a la Ilustración, imbuido de liberalismo, pero entonces se consideraba como algo naturalmente establecido ${ }^{8}$. La concesión real (el octroi) o la prohibición severa, toman el relevo a las relaciones espontáneas entre partes; a eso lo llamamos política mercantilista. El mercantilismo es, esencialmente considerado, la filosofía del control espacial sobre lo disperso, sobre lo heterogéneo ${ }^{9}$. Prueba de ello es que las barreras internas son a veces más inflexibles que las externas, porque aún no hay mercado interior propiamente dicho. Pareciera a primera vista que el mercantilismo fue una política pensada para el desarrollo del mercado interior. Pero consiste más bien en prohibir lo ajeno, pues de lo contrario hubiera fomentado el propio mercado. Que tal cosa no sucediera nos pone en la pista de que el mercantilismo estaba pensado para ayudar al sector público y a las actividades económicas relacionadas con él. A falta de algo mejor, los particulares habían de ir tirando con los permisos oficiales y el contrabando, muy activo. Pero tiene sus ventajas también. El Estado vehicula el paso a mercados que de otra forma

\footnotetext{
7 En efecto, al patriotismo institucional (del tipo que sea) es propio de territorios sin unificar, lo que no es el caso de España; de ahí que sea un argumento de los partidarios del federalismo o la secesión.

${ }^{8}$ A buen seguro, los hijos de la Ilustración se hubieran sentido mucho más escandalizados de conocer las barbaridades cometidas en el siglo XX.

${ }^{9}$ En el Sacro Romano Imperio se practica el cameralismo, que pone el acento la administración de un espacio controlado y cercano, puesto que el poder central es débil y no existe dispersión territorial.
} 
estarían cerrados o serían difíciles de ocupar por parte de comerciantes y financieros. Además, dispone de fuerza coercitiva superior a la de los particulares, y cuenta con capital espacial para contentar a los súbditos más activos. En el caso concreto de los Países Bajos obedientes, se pretendió disponer asimismo de capital financiero para los particulares a través de los Montes de Piedad, organismos que ya habían demostrado su eficiencia en otras latitudes pero que no lograrán levantar el decaído mercado interior de las provincias flamencas en una coyuntura tan delicada ${ }^{10}$.

Mientras los poderes guerrean para amortiguar en lo posible los efectos del conflicto, grupos humanos se trasladan de un lugar a otro en busca de seguridad y tranquilidad. Es bien conocida y evaluada la corriente sur-norte desde el comienzo de la rebelión de los Países Bajos, con un desplazamiento importante de capital humano en beneficio del bando rebelde. Menos conocida y por consiguiente peor evaluada es la migración procedente de la Guerra de los Treinta Años, cuando los habitantes de la sufrida Centroeuropa (especialmente el Imperio) tuvieron que dejar sus tierras y pertenencias buscando un clima social y económico mejor. La migración tiende a agruparles por creencias religiosas; en el bando protestante, las Provincias Unidas e Inglaterra fueron las tierras de promisión. Nunca se pondrá bastante el acento en la importancia de la batalla de la Montaña Blanca ( 8 de noviembre de 1620), tras de la cual una masa de gentes no afectas al dogma católico, muchos de ellos hugonotes, huyen de Bohemia y regiones adyacentes pensando encontrar su salvación en occidente. Son gentes de habilidades técnicas notables en astronomía y mecánica ${ }^{11}$; conocer su aportación a los países de acogida espera todavía un estudio en profundidad. En las Provincias Unidas el flujo migratorio no dejará de crecer hasta el pico de 1650-80, un incremento que solo se igualará y aun superará en el siglo $X X^{12}$.

Tras largos decenios, se sale por fin del impasse hispano-holandés cuando los contendientes se conceden el reconocimiento mutuo en la paz de 1648. El Tratado de Münster buscaba estabilizar los espacios, aunque en el caso de los Países Bajos españoles, la ambición de Luis XIV conseguirá mermar territorio al rey católico. En el norte, la burguesía impuso un sistema

\footnotetext{
10 Existe abundante bibliografía sobre los Montes de Piedad en los Países Bajos Meridionales. Citar la ardiente defensa que hace de ellos Jean Boucher, L'usure ensevelie ou défence des Monts de Piété, (Bruxelles, 1628). En cuanto a modelos, destacar a Paul Soetaert, De Berg van Charitate te Brugge, een stedelijke leenbank (1573-1795), (Brussel: Pro Civitate, 1974) y De Bergen van Barmhartigheid in de Spaanse, de Oostenrijkse en de Franse Nederlanden, (Brussel: Gemeentekrediet van België, 1986). Una visión general y sus fondos de archivo, en Micheline Soenen, Institutions centrales des Pays-Bas sous l'Ancien Régime, (Bruxelles: AGR, 1994), pp. 546-553.

${ }^{11}$ Miguel Ángel Echevarría Bacigalupe, En los orígenes del espacio global. Una historia de la mundialización, (Madrid, Eds. de La Catarata, 2013), pp. 165-166.

12 En la etapa $1650-80$, un $8 \%$ de la población de las Provincias Unidas era de origen extranjero. Jelle Van Lottum, "Les migrations internationales dans I'Europe du Nord-Ouest", en Les circulations internationales en Europe, années 1680-années 1780, dir. Pierre-Yves Beaurepaire y Pierrick Pourchasse, (Rennes: Presses Universitaires, 2010) p. 28.
} 
republicano de corta duración; en verdad, los neerlandeses nunca habían hecho ascos a la monarquía de poderes limitados, y tras la experiencia de los hermanos De Witt, las cosas inclinaron hacia la constitución de un régimen monárquico (primero de facto, luego de iure). En el sur, la debilidad del gobierno central se acentuaba a cada día, y eso permitió por un lado el acercamiento a los antiguos enemigos de las Provincias Unidas, y por el otro un mayor autonomismo en las provincias meridionales ${ }^{13}$. Hubo entonces signos de cambio, lento pero perceptible, hacia una mayor participación del sector privado en los asuntos públicos. Las Cámaras de Comercio, entes semipúblicos desde $1665^{14}$, estarán ligadas a esa creciente autonomía, así como otras instituciones económicas o de fomento técnico emprendidas durante el reinado de Carlos II, en consonancia con las inquietudes de la Europa de su tiempo ${ }^{15}$. Debe reseñarse una pérdida sensible, la del Almirantazgo de los Países Septentrionales en 1694, pero hubo quienes no se rindieron a la adversidad. Frente al "partido español" o defensor del inmovilismo institucional, se encontraba el partido reformista liderado por el conde de Bergeyck y el marqués de Bedmar, cercanos ambos al reformismo francés de Colbert. Las peleas entre facciones menudearon y se hicieron más intensas conforme avanzaba el fin de siglo ${ }^{16}$. Las reformas económicas de Bergeyck-Bedmar fracasaron ante la oposición de los tradicionalistas; la Guerra de Sucesión Española les dará otra vez alas hasta que el bando de Felipe $\mathrm{V}$ sea expulsado de Flandes. La reactivación económica, especialmente la comercial, habrá de esperar al nuevo régimen austríaco y a la nueva coyuntura internacional que deja atrás la crisis del Seiscientos.

Es importante señalar cómo el sector privado, tan maltrecho hasta entonces, va a ser objeto de atención por parte de los poderes públicos, que ven en él un medio de acrecentar la riqueza y el poder. Entramos en un nuevo periodo, donde se regula el comercio como antes, pero haciendo participar en las instituciones a diversos particulares y aun fomentando el carácter privado de algunos organismos económicos, especialmente las compañías mercantiles, los consulados y en algunos casos las bolsas de comercio, todo lo cual, vía interconexión, va tomando día a día el relevo de las antiguas ferias $^{17}$. El modelo a imitares el inglés, seguido del holandés, pero el conflicto

\footnotetext{
13 Miguel Ángel Echevarría Bacigalupe, Flandes y la Monarquía Hispánica, 1500-1713, (Madrid: Sílex, 1998), pp. 379-380.

${ }^{14}$ Sobre el periodo español, ver Piet Lenders, "Les Chambres de Commerce dans les Pays-Bas Méridionaux sous I'Ancien Règime", en Entre mission publique et intérêts privés. Histoire des Chambres de Commerce en Belgique (XVIIe-XXe siècles), coord. C. Vancoppenolle, (Bruxelles: AGR, 1995), pp. 14-19.

${ }^{15}$ Más que en la Universidad, el progreso científico y técnico recayó en instituciones informales como las academias. Roy Porter, "La Revolución Científica y las Universidades", en Historia de la Universidad en Europa, ed. H. de Ridder, (Leioa, UPV, 1999), p. 588.

16 Miguel Ángel Echevarría Bacigalupe, "La Guerra de Sucesión en los Países Bajos meridionales. Antecedentes, desarrollo y consecuencias, en La Guerra de Sucesión Española, eds. F. Edelmayer, V. León Sanz y J.I. Ruiz Rodríguez, (München-Wien: Oldenbourg, 2008), p. 303.

17 La Monarquía Hispana fue actor privilegiado en este proceso. Cf. por ejemplo Ana Crespo Solana, Mercaderes atlánticos. Redes del comercio flamenco y holandés entre Europa y el Caribe, (Córdoba, Universidad, 2009).
} 
hacía complicado avanzar. El final de las terribles guerras del siglo XVII favoreció la expansión sin duda, haciendo posible la creación y sobre todo el mantenimiento de instituciones cercanas a la actividad comercial y financiera. Claro está que no hay que lanzar las campanas al vuelo. Los límites impuestos por el sistema absolutista, la situación de conflicto y los inconvenientes de la economía preindustrial, harán que este tipo de asociaciones y de llamadas a lo privado queden por debajo de las expectativas.

Uno de los objetivos proclamado insistentemente desde los últimos decenios del XVII tendrá por raíz una seria atención al mercado interior, hacia el cual los países del occidente europeo fueron dirigiendo sus miradas. La expansión hacia territorios en ocasiones muy alejados del centro, hizo que los poderes y la opinión pública se plantearan una revitalización de la economía metropolitana para no perder, en caso contrario, el control de sus posesiones exteriores. Nace un nuevo espíritu que llevará en Inglaterra a la revolución industrial y en otros países del entorno a crear la nación-estado acompañada de un mercado interior más vinculado entre sí. Tarea fácil de plantear sobre el papel pero muy complicada de llevar a cabo, como el tiempo demostrará, pues a los inconvenientes físicos (geografía, topografía) se unían los institucionales, tanto o más problemáticos de eliminar. Para el caso de los Países Bajos, se dio una clara dicotomía. En las provincias separadas, eso que llamamos identidad nacional fue posible gracias a la afirmación frente a la monarquía española y luego al poder Habsburgo; solo existía un problema, el acusado particularismo de las provincias. Hubo por eso que esperar al siglo XIX para ver aparecer un Reino de Holanda como estado moderno acorde con su tiempo ${ }^{18}$. En cuanto a las provincias meridionales, podríamos caracterizar su situación como de identidad negativa: no saben bien lo que son, pero saben lo que no son. Tierra de frontera, no son protestantes ni republicanos, ni se sienten holandeses, alemanes o franceses, pero tampoco son "belgas", sino dos comunidades de lengua y cultura distintas. Esta afirmación de su negatividad (valga lo contradictorio del concepto) persistirá en el tiempo, incluso tras la proclamación en 1830 del Reino de Bélgica. Hoy aún son bien visibles las huellas de esa peculiar situación.

\section{3.- El siglo XVIII, o la transición hacia el mercado interior}

Los contemporáneos tenían clara la relación entre paz y crecimiento. Porque la guerra es un arma de doble filo: beneficia solo a unos pocos y hace irregular la ganancia. Pero un sistema económico tan versátil a corto plazo como el del Antiguo Régimen portaba en su seno la semilla del conflicto; el hambre y las privaciones llevaban consigo implícita la violencia. Solo la mejora de la coyuntura tras un atroz siglo depresivo, más la formación de

18 La problemática de las Provincias Unidas, en J. L. Price, The Dutch Republic in the Seventeenth Century, (New York: St. Martin's Press, 1998), pp. 61-69. 
espacios propios que las naciones se van a reconocer entre sí, permitirá una normalización de las actividades materiales y la consolidación de esa tendencia hacia la formación del mercado interior. El XVIII traerá aquella ansiada paz que hará posible el beneficio y aun el progreso.

La lógica expansiva que impulsa la economía occidental hallará fuertes obstáculos. La dispersión, de beneficiosa estaba convirtiéndose en insoportable. Había que mimar el espacio propio, la "madre patria", lo que generó un movimiento en los principales países de Europa occidental hacia lo que luego será el esquema Nación-Estado-Mercado (NEM) concretado tras las revoluciones burguesas ${ }^{19}$. Anticipaciones reseñables fueron los estados francés y español, o en distinto sentido, la política de fomento interno que adoptará Inglaterra tras la Revolución de 1688, y que le convertirá en una gran potencia política y económica después de 1770 . Pero salvo en el caso inglés, había reticencias importantes a unificar el mercado interior. Primero, por la posición privilegiada de las élites, especialmente la nobleza y el clero, que mantenían el poder junto a una corona de carácter absolutista, y a quienes no convenía un cambio sustancial de su privilegiada situación. Unificar mercados, legislaciones e instituciones políticas y administrativas, levantó pues una ola de rechazo. De ahí que los esfuerzos por crear una red eficiente de comunicaciones se estrellaran no tanto contra los contratiempos de la orografía y el clima, cuanto especialmente contra el temor al cambio en algunos estamentos privilegiados.

Pero los que gozaban de beneficios no estuvieron solos en su boicot obstruccionista. Germano Maifreda expone cómo en el siglo XVIII cualquier intento de levantar divisorias encontraba hostilidad en la población de buena parte de Europa, que veía en los agrimensores un enemigo a evitar ${ }^{20}$. Lo que se extendió evidentemente a los territorios fronterizos, tan sensibles como poco delimitados. Tendrán que llegar nuevos tiempos para que, tras profundos cambios institucionales, no siempre pacíficos por cierto, cada nación-estado determine por la fuerza establecer sus límites internos y externos.

A estas características sigue perteneciendo el modelo de los Países Bajos. En los meridionales, Austria, la nueva potencia ocupante sucesora de los Habsburgo españoles, saldrá en principio beneficiada por la anexión de ese territorio. De hecho, sin embargo, los más favorecidos fueron los príncipes alemanes vecinos y en cierto modo las Provincias Unidas, quienes a los privilegios comerciales obtenidos en los tratados de paz añadieron su presencia militar gracias a las "Plazas de la Barrera". La verdad es que el Flandes austriaco se mantuvo ajeno a las preocupaciones de la corte imperial, mucho más interesada en la expansión hacia la península italiana. Si bien

19 Sobre esta tendencia centrípeta, cf. Echevarría Bacigalupe, En los orígenes, pp. 141-150.

20 Germano Maifreda, From Oikonomia to Political Economy. Constructing Economic Knowledge from the Renaissance to the Scientific Revolution, (Surrey: Ashgate, 2012), pp. 70-71. 
hubo un representante del poder central en Bruselas, fue respetada la autonomía de que gozaran las provincias ${ }^{21}$.

Cierto asimismo que en Viena se creó el año 1717 un Consejo Supremo de los Países Bajos, pero la tradición española, incluido el idioma castellano, siguieron prevaleciendo en dicha institución, que, tras llevar una vida accidentada, fue disuelta en $1757^{22}$. En todo caso, la victoria austríaca supuso el mantenimiento de las instituciones tal y como se había venido haciendo desde tiempo atrás. La consideración de provincias periféricas a los intereses Habsburgo ${ }^{23}$ dio alas a la regeneración autónoma de los Países Bajos católicos, no visible hasta la tercera década del XVIII y con diferentes alternativas $^{24}$. Pero por lo mismo, ni el sur ni las Provincias Unidas dieron signos de cambio institucional relevante en buena parte del siglo, incluidos los decretos de modernización por parte de la emperatriz María Teresa desde 1747. En esa época, el funcionamiento de los mecanismos tradicionales de poder también perpetuó en la república neerlandesa el sistema instaurado en tiempos de la rebelión contra España ${ }^{25}$.

No cabe duda al respecto: ambas partes habían cobrado con el tiempo personalidad propia que les diferenciaba de terceros, fueran franceses o imperiales. En el norte, ese problema ya se había resuelto hace tiempo, con la doble independencia de España y del Imperio tras la paz de Westfalia. La vigorosa personalidad de cada provincia se vio atemperada en lo económico por la facilidad que aportaba la geografía. Un lugar particularmente sensible para esto fue el delta de los ríos, o por mejor decir los deltas, a saber, el formado por el Escalda, el Mosa y el Rin (con Middelburg, Dordrecht y Rotterdam como ciudades más relevantes), el Zuiderzee (con Ámsterdam como principal enclave), y el área Lauwers-Dollard-Ems (con Groningen y Emden como puntos de referencia). Los tres deltas terminarán por formar con los siglos una unidad económica cada vez más estrecha y potente, muy en especial desde que la economía marítima local se añada a la expansión internacional del comercio y los medios de transporte entre 1570 y 1650

21 Michèle Galand, "Pouvoir et circulations internationales: les Pays-Bas autrichiens dans l'espace habsbourgeois et dans l'espace européen", en Les circulations internationales en Europe, années 1680-années 1780, eds. P.-Y. Beaurepaire y P. Pourchasse, (Rennes: Presses Universitaires, 2010), p. 469.

22 Michel Baelde y René Vermeir, "Conseil Suprème des Pays-Bas à Vienne", en Les institutions du gouvernement central des Pays-Bas Habsbourgeois, (Bruxelles: AGR, 1995), pp. 109-110. $23 \mathrm{Ni}$ siquiera fueron incorporadas a la administración financiera de la monarquía. Jean Bérenger, Les Habsbourg et l'argent. De la Renaissance aux Lumières, (Paris: PUPS, 2014), p. 11.

${ }^{24}$ M. de Neny, secretario de Estado y de Guerra en Bruselas, desestima en 1727 la creación de un consulado en Bilbao para transportar desde allí lanas a Flandes (desde donde venderlas a Europa) por la pequeñez de los negocios con España, junto con la rivalidad holandesa e inglesa en el comercio internacional. Archives Générales du Royaume à Bruxelles, Manuscrits Divers, leg. 2268, s.f.

${ }^{25}$ E.H. Kossmann, "The Dutch Republic in the Eighteenth Century", en The Dutch Republic in the Eighteenth Century, eds. M.C. Jacob y W.W. Mijnhardt, (Ithaca: Cornell University Press, 1992), p. 28. 
aproximadamente ${ }^{26}$. El proceso de integración espacial culminaría en la segunda mitad del XVII, cuando Ámsterdam y Rotterdam centralicen la principal actividad económica de la zona, constituyéndose asimismo en centros clave para negocios e información a ellos relativa ${ }^{27}$, con las ventajas que eso supone para la rebaja de los costos transaccionales. La situación no cambiará en el XVIII; sin embargo, la tercera guerra anglo-holandesa (178183) y el dominio napoleónico van a suponer transformaciones que marcarán una nueva era para el comercio y el transporte entre los deltas y de cara al exterior, caracterizada en general por el declive. Un típico movimiento espacial, en suma.

En cuanto al sur, no tenía necesidad de demostrar por el momento que su personalidad era incompatible con el régimen político de turno. Pero de ahí a hablar de nación, hay todavía un trecho. Es cierto que las relaciones económicas entre las provincias meridionales se habían incrementado mucho, y que en cierto modo se puede hablar de un mercado interior. Un buen número de carreteras fue creado en los Países Bajos meridionales en estas décadas, lo que provocó abaratamiento de los costes de transporte y facilidad de tránsito, factores que sin duda ayudaron a conectar las diferentes partes del conjunto ${ }^{28}$; del mismo modo, los precios interiores tendieron al equilibrio hasta $1789^{29}$. Aunque son datos a tener en cuenta, no constituyen pruebas suficientes para concluir la formación de un área política compacta asumida como tal desde dentro y desde fuera. Porque si miramos a lo hacendístico, vemos que tales circunstancias no repercutieron en la mejora del nivel de vida de la gente, que hubo de soportar alta presión fiscal dentro de una gran disparidad impositiva sin que nadie levantara la voz contra tales injusticias, signo aparente de falta de conciencia grupal ${ }^{30}$. Lo mismo cabe hablar de la desigualdad entre las provincias: si en el XVII Brabante soporta más cargas fiscales $^{31}$ en la centuria siguiente el peso recaerá sobre Flandes ${ }^{32}$. ¿Qué podemos concluir de todo lo arriba dicho? No nos es dado calibrar algo intangible como la "conciencia nacional", según han tratado de hacer otros ${ }^{33}$, tanto por su dificultad intrínseca ${ }^{34}$ como porque aquí estamos hablando de hechos económicos, y no de sentimientos. En nuestra opinión, las manifestaciones a que hemos aludido pueden significar una cosa: que el

26 Werner Scheltjens, Emergence, Functions and Structure of the Low Countries' Maritime Transport System, ca. 1300-1850, (Leiden: Brill, 2015), p. 41.

27 Ibid. p. 48.

28 E. Buyst, S. Dercon y B. van Campenhout, "Market integration in the Southern Low Countries in the second half of the 18th Century", en Integration of commodity markets in History ed. C.E. Núñez, (Sevilla: Universidad, 1998), p. 31.

29 Ibid., pp. 32 y 40.

30 P. Janssens, H. Verboven y A. Tiberghien, Drie eeuwen Belgische Belastingen, (Brussel: Colofon, 1990), p. 122.

31 Echevarría Bacigalupe, Flandes y la monarquía, pp. 372-373.

32 Janssens, Verboven y Tiberghien, op. cit., p. 68.

33 Merece la pena consultar el libro de S. Dubois, L'invention de la Belgique: genèse d'un Etatnation 1648-1830, (Bruxelles: Eds. Racine, 2005).

34 Es la misma diferencia entre nivel de vida (educación, sanidad, tasa de empleo, salarios, precios, transporte...), que se puede cuantificar, y calidad de vida (mayor o menor satisfacción), que no se puede. 
periodo de maduración no parece haber cristalizado aún en una "conciencia nacional" activa, traducible en hechos concretos. Hace falta un reactivo. Tendrán que llegar acontecimientos externos para que esa conciencia derive en la voluntad de crear un Estado-nación.

Esos acontecimientos externos pueden dividirse en dos: la política del emperador José II (1765-1790) y el impacto de la revolución francesa. José II, muy popular en los Países Bajos meridionales por haber abolido las fortificaciones holandesas de la Barrera, impuso sin embargo una nueva política que amenazaba con romper el orden establecido, tanto en lo espiritual (catolicismo) como en lo material (producción, financiación y distribución ligadas a mercados tradicionales). En efecto, el emperador llevó a cabo un movimiento centralizador desde 1787 que su madre María Teresa no se había atrevido a efectuar. Las medidas son bien conocidas: reducción de la autonomía de los poderes locales, mayor vinculación con Viena, abolición de la servidumbre, reforma judicial, y lo más sorprendente, igualdad de cultos al estilo del Imperio frente al catolicismo monolítico que imperaba en Flandes y Valonia desde el XVI. Económicamente hablando, se liberalizaron los mercados, aunque bien es cierto que, como queda dicho, la vinculación entre aquellos ya era ostensible en las décadas centrales del siglo. De nuevo la resistencia de los poderes locales se hizo sentir, como no podía por ser menos, y se tradujo en la revolución brabanzona de 1790, por la que se creó la Confederación de los Estados Belgas Unidos que representaban a la "nación Bélgica" ${ }^{35}$; la denominación "Estados Belgas Unidos" contiene en sí misma el fondo de diversidad provincial y recuerda evidentemente el ejemplo de la joven república americana surgida de las trece colonias británicas de Norteamérica. En 1792 Lieja se unirá a los "belgas". Para 1794, nuevo e importante acontecimiento: los Estados Belgas formaron en adelante parte de la República Francesa, y luego del imperio napoleónico hasta 1815, en que Bélgica fue anexionada a Holanda, de la que se separaría apenas quince años después.

Si bien los referidos acontecimientos externos determinaron la eclosión de la nueva nacionalidad, ello tampoco hubiera sido posible sin una distinta percepción de las cosas que viene determinada por el repliegue desde los grandes espacios a los espacios nacionales que componían aquellos. Se está dando paso pues a la Nación-Estado-Mercado que deseaban los enemigos del imperialismo austríaco, español o napoleónico.

Hay en esta cuestión unos componentes ideológicos y de mentalidad colectiva que dada su amplitud sería imposible de concretar en estas pocas páginas. Debemos sin embargo hacer hincapié, dada su relevancia, en el papel que jugó un filósofo, Johann G. Fichte, sobre esa toma de conciencia. Fichte, animador del movimiento nacionalista patrio con sus Discursos a la

35 Los hechos, en Charles Terlinden, Histoire militaire des Belges, (Bruxelles: La Renaissance du Livre, 1966), vol. 1, p. 219. 
nación alemana (1806), y enemigo jurado de las pretensiones napoleónicas de dominar Europa ${ }^{36}$, defendía una manera de ver las cosas que tiene mucho que ver con el objetivo de nuestro trabajo. Nos centramos para evidenciarlo en una obra que merece ser muy tenida en cuenta dentro del pensamiento económico, aunque se la pueda considerar de segundo orden frente a las aportaciones de Adam Smith o del mismo Friedrich List. Nos referimos a El Estado comercial cerrado, escrito en 1800 y donde el filósofo sajón preconiza una organización estatal sobre la base nacional, de carácter autárquico y con una economía estrictamente planificada ${ }^{37}$. Antecesor de las teorías estatales de extrema derecha y extrema izquierda posteriores, es sumamente interesante porque de hecho consagra lo que hoy llamamos economía nacional.

Fichte argumenta $^{38}$ que Europa ha venido formando desde el primer medievo un todo indisoluble basado en las instituciones germánicas y la cultura latina, con el Emperador y el Papa como figuras clave. Tras la Reforma y la aparición del Estado moderno, tal unidad se disgregó, salvo en una cosa: el trato o comercio, que seguirá siendo universal. Por eso, dice el filósofo, hay que terminar con ese último vestigio mediante la nación económicamente autárquica que ponga el broche a la ruptura religiosa y política. Esta interpretación revela a las claras la toma de posición ideológica hacia la trilogía Nación-Estado-Mercado que termine con la herencia medieval. Las relaciones económicas internacionales no son sino el resto de aquella visión universalista que debe perecer, pero que está resurgiendo con el imperio de Napoleón. La alternativa ha de ser pues un NEM cerrado al exterior o mínimamente dependiente, una entidad ajena a sus vecinos como si fuesen las mónadas de Leibniz, y controlador de la vida de sus habitantes. Así se habrá consumado la separación iniciada a comienzos del siglo XVI. Muchos coetáneos verán en esta propuesta un modelo a seguir. Solamente hemos de hacer un inciso obligado: Fichte y sus coetáneos piensan sobre todo en un Estado de base esencialmente mercantil, pues la revolución industrial apenas empezaba a despuntar en Inglaterra. Los británicos representaban una gran nación comercial apoyada por sus manufacturas, no una nación industrializada con redes de comercialización. De una u otra forma, las áreas antes agregadas a destinos ajenos verán en el nacionalismo una ideología para autoafirmarse en el XIX, una centuria de mucha mayor complejidad económica que los precedentes. Entre los que aceptan dicho pensamiento, estaban por supuesto los Países Bajos, en especial los del sur.

\footnotetext{
${ }^{36}$ En 1813, Fichte dejó sus tareas académicas para enrolarse en la milicia contra el emperador de Francia.

37 Johann G. Fichte, El Estado comercial cerrado ed. J. Franco Barrio, (Madrid: Tecnos, 1991). 38 Ibid., pp. 81-87.
} 


\section{4.- Estado nacional e instituciones económicas}

Las revoluciones de fines del XVIII habían dado la señal de partida para el estado nacional. Tras la derrota de Napoleón en 1815, parece haber llegado la hora de saldar cuentas con el espacio amplio, al que se augura una vida limitada. Desde entonces varias grandes monarquías, alguna de carácter imperial, se fragmentaron en nuevas patrias, mientras que las colonias reclamaban su personalidad propia e individualizada bajo el concepto de pueblo-nación. En cuanto a la política económica, tendrá dos grandes ejes: creación del mercado interior, y conquista del mercado exterior, aunque buscando pasar del sistema comercial al industrial. Esa será la tarea del mundo desarrollado en el siglo XIX y parte del XX.

Las "provincias belgas" no podían ser una excepción a este fenómeno histórico, antes, al contrario. Como gran potencia comercial del ayer, aunque limitado su radio de acción al presente por una influencia británica más abrumadora cada día, este Reino de Bélgica era muy consciente de la importancia de consolidar su espacio interno según el modelo inglés, para llevar a cabo el drenado continuo de recursos propios y ajenos con el fin de entregarlos ya transformados al mercado, en un movimiento constante de expansión-regresión. Independiente desde 1830, Bélgica lo tuvo más fácil que otros países del entorno, entre ellos la vecina Holanda. Redes comerciales con el exterior, maduradas durante siglos, permitieron al nuevo país importar lo necesario para fundamentar su crecimiento y posterior desarrollo. La pericia y abundancia de sus artesanos en el ramo del textil venía provocando desde hacía siglos la admiración general en toda Europa y aún más allá. Felizmente, contaba asimismo con yacimientos de hierro y carbón, un sector en el que también poseía experiencia, tanto en las ferrerías tradicionales como en el manejo de los altos hornos. La tradición financiera jugó de nuevo a su favor: ya desde 1822, la Société Générale aseguraría el apoyo crediticio, lo que culminará en 1835 con la creación de la Banque de Belgique. Canales, ferrocarriles y en menor medida carreteras pusieron el broche de oro al proceso. Una sola cosa no terminaba de casar: la existencia de dos comunidades de lengua distinta. En el Antiguo Régimen esto no había sido un inconveniente, porque el sistema se integraba en torno a la persona del soberano. Para el NEM sí lo era, porque la soberanía, en tanto que global (nación soberana), se concebía como exclusivista. Por el momento, el triunfo de una de las partes, la francófona, garantizaba la continuidad del esfuerzo en pro de la nueva nacionalidad. También simplificaba la problemática el carácter oligárquico del poder, donde el pueblo llano apenas tenía representación. Pero todo eso no iba a durar para siempre; la que llamaríamos "ambigüedad del corredor" terminará por plantearse precisamente en nombre del mismo principio nacionalista que propició la formación del nuevo país. 
Holanda, desprendida de las provincias meridionales de los antiguos Países Bajos, se debatirá entre las ventajas y los inconvenientes de modernizarse. Abandonado el peculiar régimen republicano por el monárquico, más en consonancia con los tiempos ${ }^{39}$, pasar al NEM resultará más fácil allí que en la nación vecina del sur, por la mayor coherencia económica, cultural y lingüística ya aludidas. Sin embargo, la tradicional autonomía de las provincias iba a lastrar el proceso unificador. Por otro lado, de un gran poder comercial había derivado en potencia financiera, actividad que le puso a la cabeza de las naciones europeas en PIB per cápita ${ }^{40}$, pero que le impidió saltar al mundo industrializado precisamente por la ausencia de aquello que sobraba a los belgas: tradición manufacturera. Habrá de esperar a la segunda revolución industrial, terminando el siglo XIX, para ponerse al día, crecer y desarrollarse ${ }^{41}$.

\section{5.- Conclusiones}

Nos hemos movido en una etapa histórica caracterizada por lo que podríamos denominar la conquista del espacio, o por mejor decir, de los espacios. Europa occidental, presa de sus insuficiencias y contradicciones internas, escapa hacia adelante pretendiendo encontrar en el horizonte respuesta a aquellas. Plus Ultra era el lema de España, pero podría haberse extendido sin problemas a la Europa atlántica. Esa dispersión lleva a los Países Bajos a recorrer longitudinalmente el pasillo Mar del Norte-Italia septentrional. Luego, incluida dentro de la Monarquía Hispánica, participará de las inquietudes europeas de aquella, quien la transportó asimismo por las cuatro esquinas del planeta haciéndola partícipe de la primera mundialización, pero a costa de sumirla en la honda crisis de un conflicto bélico sin aparente fin que menoscabó su potencialidad. Adscrita luego a la monarquía vienesa como provincia periférica, su suerte de hecho no fue a cambiar hasta el desmoronamiento del poder Habsburgo a finales del XVIII ante el empuje francés y la extensión del sentimiento nacionalista.

Esto nos permite percibir dos pautas distintas y en mucho contrapuestas. El sistema comercial propio del primer capitalismo era expansivo (por el "efecto necesidad") y necesariamente plural, como plurales eran los espacios que abarcaba. Quien no se acomodaba a él, es porque quería hacerse uno especialmente a su medida; tal fue el caso de los holandeses y los ingleses. Sin embargo, desde finales del XVII sonó la voz de alarma: se había ido demasiado lejos; las capacidades propias se estaban sacrificando a intereses

\footnotetext{
${ }^{39} \mathrm{Al}$ viejo republicanismo, que tan bien había venido funcionando en el pasado, se le achacarán todos los problemas y retrasos de la modernización; J. L. Price, op. cit., p. 61.

${ }^{40}$ Si los Países Bajos alcanzan en 1820 los 1.838 \$ per cápita, Gran Bretaña llegará solamente a los 1.706 (estimado todo en \$ de 1990); cf. Angus Maddison, The World Economy. A Milennial Perspective (Paris: OECD, 2002), p. 185.

${ }^{41}$ Para más detalles sobre el tardío crecimiento holandés, cf. Michael J. Wintle, Economic and Social History of the Netherlands, 1800-1920, (Cambridge: CUP, 2000).
} 
cada vez más lejanos que podían absorber las fuerzas de la metrópoli en su propio detrimento. O sea, el centro se arriesgaba a perder el control de su periferia; España y Portugal estaban dando ya un peligroso ejemplo. Inglaterra ejecutó el primer viraje de timón hacia la constitución de un auténtico mercado interior capaz de asimilar y transformar desde sí mismo los recursos propios y los ajenos gracias a los capitales humano y físico obtenidos del entorno inmediato. Concentrar espacialmente las actividades económicas para después dirigirlas de nuevo hacia el exterior, he ahí el movimiento táctico efectuado. La experiencia salió tan bien, que dejó en un segundo plano a sus rivales, entre ellos las Provincias Unidas, quienes languidecieron en medio, paradójicamente, del esplendor financiero. Los Países Bajos meridionales, austríacos por el momento, irán preparando silenciosamente su propia unidad dentro del Sacro Romano Imperio al amparo de la razonable quietud de las relaciones internacionales y las ventajas de la coyuntura alcista. El movimiento retráctil se dirigió hacia una nación-estado-mercado, pero todavía dentro del sistema mercantil antiguo. Lo que ocurrirá sería algo distinto, nada menos que la revolución industrial, cuyo ejemplo estaba justo al otro lado del Canal de la Mancha.

La voluntad de imitar el proceso industrializador de Inglaterra (la llamada Gran Divergencia) añadirá en las provincias meridionales razones para conseguir un Estado propio y su cohorte de instituciones, fuera ya del Imperio y aun de la unión con los vecinos septentrionales de las Provincias Unidas, obligada por el Congreso de Viena. Así se configuró el nuevo Reino de Bélgica: como nieto de la expansión, e hijo de la contracción territorial. Las nuevas instituciones van a ser "nacionales", propias del país y que afectan al conjunto de los ciudadanos. Desbordando el ámbito meramente comercial y financiero, añadieron a sus competencias la notable actividad manufacturera y distribuidora que se estaba desarrollando. Una vez ocupado el espacio interior, se dirigirán las miras a la conquista económica de los vecinos y de terceros países, ayudándose a la vez del movimiento colonialista, proveedor de un espacio de reserva juzgado indispensable. Los neerlandeses tendrán que esperar su oportunidad para crecer y desarrollarse. Aunque salga del objetivo marcado, no me resisto a comentar que el NEM belga demostrará a medio plazo sus limitaciones, entre ellas la existencia de dos nacionalidades muy marcadas en un mismo territorio que en principio debería ser unitario, y la rivalidad internacional salida de la atomización del espacio políticoeconómico. En el siglo XX habrá de ser asumido por una nueva agregación, que se concreta en el Mercado Común Europeo, luego Unión Europea. Otra vez más el movimiento expansivo ordenando el cambio de perspectivas.

¿Ha terminado su marcha ese constante vaivén? El nacionalismo (más bien regionalismo) en auge desde finales del XX dirá que no, que ahora es preciso conquistar el espacio interior, pero para dividirlo de nuevo. El futuro tendrá la palabra, aunque las leyes del espacio histórico nos indican en principio una tendencia tan inexorable como clara. Aprendamos del pasado, pero no para 
reproducirlo, sino porque nos indica las tendencias clave, y nos marca el porvenir. 
Bibliografía:

Baelde y Vermeir 1995: Michel Baelde y René Vermeir, "Conseil Suprême des Pays-Bas à Vienne", en Les institutions du gouvernement central des PaysBas Habsbourgeois, (Bruxelles: AGR, 1995), pp. 109-110.

Bérenger 2014: Jean Bérenger, Les Habsbourg et l'argent. De la Renaissance aux Lumières (Paris: PUPS, 2014).

Boucher 1628: Jean Boucher, L'usure ensevelie ou défence des Monts de Piété, (Bruxelles, 1628).

Buyst, Dercon y van Campenhout 1998: E. Buyst, S. Dercon y B. van Campenhout, "Market integration in the Southern Low Countries in the second half of the 18th Century", en Integration of commodity markets in History ed. C.E. Núñez, (Sevilla: Universidad, 1998).

Crespo Solana 2009: Ana Crespo Solana, Mercaderes atlánticos. Redes del comercio flamenco y holandés entre Europa y el Caribe, (Córdoba: Universidad, 2009).

De Schepper 1987: Hugo de Schepper, 'Belgium Nostrum' 1500-1650. Over integratie en desintegratie van het Nederland (Antwerpen: De Orde van den Prince, 1987).

Dubois 2005: S. Dubois, L'invention de la Belgique: genèse d'un Etat-nation 1648-1830, (Bruxelles: Eds. Racine, 2005).

Echevarría Bacigalupe 1995: Miguel Ángel Echevarría Bacigalupe, Alberto Struzzi, un precursor barroco del capitalismo liberal, (Leuven: Universidad, 1995).

Echevarría Bacigalupe 1998: Miguel Ángel Echevarría Bacigalupe, Flandes y la Monarquía Hispánica, 1500-1713, (Madrid: Sílex, 1998).

Echevarría Bacigalupe 2008: Miguel Ángel Echevarría Bacigalupe, "La Guerra de Sucesión en los Países Bajos meridionales. Antecedentes, desarrollo y consecuencias", en La Guerra de Sucesión Española, eds. F. Edelmayer, V. León Sanz y J.I. Ruiz Rodríguez, (München-Wien: Oldenbourg, 2008), p. 303.

Echevarría Bacigalupe 2013: Miguel Ángel Echevarría Bacigalupe, En los orígenes del espacio global. Una historia de la mundialización, (Madrid: Eds. de La Catarata, 2013).

Fichte 1991: Johann G. Fichte, El Estado comercial cerrado, ed. J. Franco Barrio, (Madrid: Tecnos, 1991). 
Galand 2010: Michèle Galand, "Pouvoir et circulations internationales: les Pays-Bas autrichiens dans l'espace habsbourgeois et dans l'espace européen", en Les circulations internationals en Europe, années 1680-années 1780, eds. P.-Y. Beaurepaire y P. Pourchasse, (Rennes: Presses Universitaires, 2010).

Hernández Esteve 1986: Esteban Hernández Esteve, Establecimiento de la partida doble en las cuentas centrales de la Real Hacienda de Castilla (1592), (Madrid: Banco de España, 1986).

Huizinga 1992: Johan Huizinga, El concepto de la Historia y otros ensayos, (México: FCE, 1992).

Janssens, Verboven y Tiberghien 1990: P. Janssens, H. Verboven y A. Tiberghien, Drie eeuwen Belgische Belastingen, (Brussel: Colofon, 1990).

Kossmann 1992: E.H. Kossmann, "The Dutch Republic in the Eighteenth Century", en The Dutch Republic in the Eighteenth Century, eds. M.C. Jacob y W.W. Mijnhardt, (Ithaca: Cornell University Press, 1992).

Lefevre 2013: Henri Lefevre, La producción del espacio, (Madrid: Capitán Swing Libros, 2013).

Lenders 1995: Piet Lenders, "Les Chambres de Commerce dans les Pays-Bas Méridionaux sous I'Ancien Régime", en Entre mission publique et intérêts privés. Histoire des Chambres de Commerce en Belgique (XVIIe-XXe siècles), coord. C. Vancoppenolle, (Bruxelles: AGR, 1995).

Lottum 2010: Jelle Van Lottum, "Les migrations internationales dans I'Europe du Nord-Ouest", en Les circulations internationales en Europe, années 1680années 1780, dir. Pierre-Yves Beaurepaire y Pierrick Pourchasse, (Rennes: Presses Universitaires, 2010).

Maddison 2002: Angus Mddison, The World Economy. A Milennial Perspective (Paris: OECD, 2002).

Maifreda 2012: Germano Maifreda, From Oikonomia to Political Economy. Constructing Economic Knowledge from the Renaissance to the Scientific Revolution, (Surrey: Ashgate, 2012).

Ostoni 2011: Marco Ostoni, "La comptabilité publique entre théorie et pratique. Le cas de Milan au milieu du XVIIe siècle" en La comptabilité publique en Europe, 1500-1850, coord. A. Dubet y M.-L. Legay, (Rennes: Presses Universitaires, 2011).

Porter 1999: Roy Porter, "La Revolución Científica y las Universidades", en Historia de la Universidad en Europa, ed. H. de Ridder, (Leioa: UPV, 1999). 
Price 1998: J. L. Price, The Dutch Republic in the Seventeenth Century, (New York: St. Martin's Press, 1998).

Scheltjens 2015: Werner Scheltjens, Emergence, Functions and Structure of the Low Countries' Maritime Transport System, ca. 1300-1850, (Leiden: Brill, 2015).

Soenen 1994: Micheline Soenen, Institutions centrales des Pays-Bas sous I'Ancien Régime, (Bruxelles: AGR, 1994).

Soetaert 1974: Paul Soetaert, De Berg van Charitate te Brugge, een stedelijke leenbank (1573-1795), (Brussel: Pro Civitate, 1974).

Soetaert 1986: Paul Soetaert, De Bergen van Barmhartigheid in de Spaanse, de Oostenrijkse en de Franse Nederlanden, (Brussel: Gemeentekrediet van België, 1986).

Terlinden 1966: Charles Terlinden, Histoire militaire des Belges, (Bruxelles: La Renaissance du Livre, 1966).

Wintle 2000: Michael J. Wintle, Economic and Social History of the Netherlands, 1800-1920, (Cambridge: CUP, 2000). 